and protection against sexual and gender based violence (SGBV) for women.

Methods We designed an online survey and posted it on grassroots volunteer social media groups in November 2015.

Results 32 volunteers responded to our survey. Most 20/32 $(63 \%)$ were short term volunteers working in a healthcare capacity $\mathrm{n}=14 / 28(50 \%)$. The average age of women reported by volunteers was $18-25$ (65\%). 19/28 (68\%) of volunteers had encountered pregnant women and 4/29 (15\%) said women disclosed sexual assault in the camp. $21 / 28$ (75\%) of the volunteers did not know how to refer women to sexual assault services. $100 \%$ of the volunteers reported inadequate protection and security measures against SGBV.

Discussion/conclusion There is inadequate security in the "jungle" camp and sexual violence has been described. As the number of makeshift transit camps continues to increase throughout Europe in the current refugee crisis, it is imperative that the minimum standards of SRH are met and that there is adequate security in place to protect against SGBV.

\section{P035 IMPROVING QUALITY OF PATIENT CARE IN A SRH SERVICE: INTRODUCTION OF ENDOMETRIAL BIOPSY FOR WOMEN WITH PERSISTENT BLEEDING PROBLEMS}

Najia Aziz*, Sujit Mukhopadhyay, Claire Bashford. Solent NHS Trust, Portsmouth, UK

10.1136/sextrans-2016-052718.89

Background/introduction National Institutes of Clinical Excellence (NICE) recommends to undertake endometrial biopsy (EB) sample in cases of persistent intermenstrual bleeding and in woman aged 45 or over with failed or ineffective treatment of heavy menstrual bleeding. Since January 2015 we introduced EB in our sexual health clinics.

Aim(s)/objectives The aim was to perform a transvaginal ultrasound (TVS), undertake sexually transmitted infection (STI) screen and offer MIRENA ${ }^{\circledR}$-IUS or other treatment options for persistent bleeding problems. This one-stop-service was meant to decrease referrals to the gynaecological service and improve a patient's journey.

Methods Retrospective analysis of all patients who underwent an $\mathrm{EB}$ over the past year was performed. Inclusion criteria were those specified by NICE. The exclusion criterion was postmenopausal bleeding.

Results Out of 300 patients who had a TVS (for bleeding or pain), 37 qualified for an EB. 8\% of patients had additional risk factors for endometrial cancer. 2 patients had a positive STI screen and were treated. $11 \%$ of patients had chronic endometritis on $\mathrm{EB}$ and the rest of the biopsies were negative. $54 \%$ of patients had a MIRENA ${ }^{\circledR}$-IUS inserted at the same visit. $78 \%$ of patients were discharged on the same day of consultation.

Discussion/conclusion Our study demonstrates that irregular bleeding problems in women presenting to sexual health clinics can be managed effectively in the same sitting. The clinician needs to be trained in TVS and EB procedures. This reduces the number of women referred to the gynaecological department for persistent bleeding problems.

\section{P036 AUDIT OF ORAL CONTRACEPTIVE PRESCRIBING IN PATIENTS WITH CARDIOVASCULAR RISK FACTORS}

${ }^{1,2}$ Stephen Bradley. ${ }^{1}$ University of Leeds, Leeds, UK; ${ }^{2}$ Foundry Lane Surgery, Leeds, UK

10.1136/sextrans-2016-052718.90
Background/introduction Foundry Lane Surgery has a practice population of 6,564 serving a young population with the high levels of deprivation, smoking and obesity.

Aim(s)/objectives To determine if any patients fulfilling UKMEC 3 or 4 due cardiovascular risk factors or a combination of two or more cardiovascular risk factors were prescribed COCP during the 6 month period $11^{\text {th }}$ July 2015 to $11^{\text {st }}$ January 2016.

Methods Reports were run on practice software SystemOne producing lists of patients who were prescribed COCP in the study period and also fulfilled UKMEC 3 or 4 criteria based on cardiovascular risk factors.

Results 201 patients were prescribed COCP in the study period under analysis. 3 individual patients (1.49\%) were identified who were prescribed COCP in this period despite fulfilling criteria for UKMEC 3 or 4 . One patients who received COCP for reasons other than contraception was excluded along with one patient for whom POP was deemed unsuitable due to porphyria. Three patients were identified who received COCP in spite of UKMEC 3 or 4. Two fulfilled UK MEC 3, one due to $\mathrm{BMI}>35$, one due to a combination of smoking and age $>35$. One patient fulfilled UKMEC4 (BMI > 35 \& smoker).

Discussion/conclusion Three patients $(1.49 \%)$ were prescribed COCP in spite of fulfilling UKMEC 3 or 4 . In two out of three of these patients a combination of risk factors was responsible. Practice IT systems could be optimised to alert prescribers of contraindications such as BMI, hypertension and smoking.

\section{P037 MEN WHO HAVE SEX WITH MEN, WHO ARE DIAGNOSED WITH A SEXUALLY TRANSMITTED INFECTION, REPORT SIGNIFICANTLY MORE CHEM-SEX: A CASE CONTROL STUDY}

${ }^{1}$ Zoe Ottaway*, ${ }^{2}$ Fionnuala Finnerty, ${ }^{2}$ Aliza Amlani, ${ }^{2}$ Joshua Szanyi, ${ }^{2}$ Nicolas Pinto-Sander, 2,3 Daniel Richardson. 'Maidstone and Tunbridge Wells NHS Trust, Maidstone, UK; '²Bighton and Sussex University Hospitals NHS Trust, Brighton, UK; ${ }^{3}$ Brighton \& Sussex Medical School, Brighton, UK

\subsection{6/sextrans-2016-052718.91}

Background/introduction The sexualised use of recreational drugs (Mephedrone, GBL/GHB, Crystal Meth) is thought to be associated with STI acquisition however there is little data showing a direct relationship.

Methods We reviewed 130 cases of MSM with an STI attending our STI service and 130 controls (MSM attending the STI service who did not have an STI) between $5^{\text {th }}$ May 2015 and $2^{\text {nd }}$ Nov 2015 (6 months). We collected demographic data, sexual behaviour, drug use and STI diagnoses.

Results In the 6-month period there were 5,013 appointments with MSM. Reported condom-less anal sex was significantly higher in cases 90/121 (74\%) compared with controls 65/122 $(53 \%)$; $\left(\mathrm{X}^{2}=11.71, \mathrm{p}<0.005\right.$, OR 2.54$)$. HIV prevalence was significantly higher in those with STIs: 71/130 (55\%) compared to those without STIs 33/130 (25\%); $\left(\mathrm{X}^{2}=23.14, \mathrm{p}<0.001\right.$, OR 3.53). Recreational drug use in the cases 38/122 (31\%) was significantly greater than in controls $20 / 125(16 \%) ;\left(X^{2}=7.88\right.$, $\mathrm{p}<0.005$, OR 2.37). In total Mephedrone was the most commonly used drug, followed by GBL/GHB.

Discussion/conclusion This data demonstrates a clear correlation between STI acquisition and recreational drug use in Men who have sex with men. Interventions to reduce party drug use should be implemented on an individual, local and national level to improve the sexual health of MSM, including reducing risktaking behaviours. 